\title{
Granites in Malaysia: from hard rock to clay minerals
}

\begin{abstract}
Tropical areas with extreme climates are host to extreme weathering processes and the weathered materials are normally left in situ with the absence of large-scale denudation processes such as glaciations. This research tries to understand the behaviour of the weathered granites in Malaysia, from hard rock to the final products, the clay minerals. Grade 1 or fresh granites were sampled from different locations in Malaysia and analysed. The residual soil above the fresh granites, which were formed from the weathering activities were also analysed. The types of clay minerals and clay-sized particle grains found from two study locations were compared. The bases of the comparisons were index properties, strength properties and the mineralogical properties. The parent rocks were also analysed to obtain the origin of the minerals formed at the later stages of weathering. It was found that the strength of the soil mass formed from the weathering processes generally depend on the clay-sized particle grains rather than the types of clay minerals. It should however be noted that only halloysites and smectites clay minerals were observed in the samples obtained from the two study locations.
\end{abstract}

Keyword: Granite; Clay minerals; Weathering 